- Options For Change proposes major changes to NHS dental services.

- The start date for local commissioning by primary care trusts (PCTs) is April 2005, less than 18 months away.

- Dentists must make the most of the opportunity to inform PCTs of the dental needs of the community.

- The public and the profession need to be reassured about the new NHS dental services for England.

\title{
NHS Dentistry: Options for Change. Impressions one year on
}

\author{
J. J. Murray ${ }^{1} \mathrm{CBE}$
}

\begin{abstract}
This article is a personal view of the document NHS Dentistry: Options For Change one year after publication. My first impression on looking at it now is a feeling that everything is still 'up in the air' despite the fact that the document was published a year ago. ${ }^{1}$ The vision for NHS dentistry described in the document for the future proposed as its main themes: 'meeting patients' needs, putting patients' interest first, developing the dental team and providing a service which would be available to everyone who wants it, including people with special needs, however they contact the NHS.'Brave words indeed, in view of the fact no real change had been officially suggested for NHS dentistry since 1948.
\end{abstract}

The report by the then Chief Dental Officer (CDO), Dame Margaret Seward, included radical changes to the General Dental Services in England, 54 years after the foundation of the NHS to achieve the themes suggested above. The report is without doubt a visionary document and the Department of Health should be congratulated on seeking to address health policy on dental services, which has 'lagged decades behind other health sectors'. The main points arising from the report have been well described in an article elsewhere in this issue of the British Dental Journal. ${ }^{2}$ The CDO proposed that the key themes and issues should be implemented through:

- demonstration sites organised with the NHS Modernisation Agency

- working with volunteer primary care trusts (PCTs) to develop commissioning options and new forms of contracting.

- developing an ICT (information and

${ }^{1}$ Emeritus Professor of Child Dental Health, University of Newcastle upon Tyne

Correspondence to: Professor J. J. Murray, 6 Regency Way, Darras Hall, Ponteland, Newcastle upon Tyne NE20 9AU Email:j.murray@ncl.ac.uk

\section{Refereed Paper}

Received 18.08.03; Accepted 15.10.03

doi: 10.1038/sj.bdj.4810778

๑ British Dental Journal 2003; 195: 627-629 communication technology) infrastructure for dentistry, which supports clinical pathways and encourages quality.

In writing this article I felt it was appropriate to reflect on the past year, consider some of the issues raised in Options for Change and assess the progress made on the priorities identified, especially in regard to how general dental practitioners think one year on, what patients are saying and the envisaged role of PCTs.

\section{HUMAN RESOURCES WITHIN THE GENERAL DENTAL SERVICES}

The key to progress in improving oral healthcare is the strength and commitment of the dental team working in the general dental services, as that is where the vast majority of the human resources are situated. This was recognised by the Dental Strategy Review Group in 1981 who described general dental practitioners as the 'lynch-pin of the dental services.. ${ }^{3}$ For this reason it is interesting to see how members of the dental team view Options for Change, and a recent letter to the Daily Telegraph by a dentist, Mr Ingham, may reflect general feeling among dentists. ${ }^{4} \mathrm{He}$ was commenting on the recent suggestion that that the imminent Health and Social
Care Bill will provide a modernised service that brings dentistry back into mainstream NHS care.

'I am afraid that I and the vast majority of my dental colleagues nationwide do not agree, and that is why we are taking steps to leave the NHS, after many years of service before this Bill is introduced in 2005. By shifting responsibility of local NHS care to the primary care trusts, the Bill is designed simply to pass the blame and burden away from government. The Health and Social Care Bill is the final nail in the coffin of NHS dentistry.'

I have no way of knowing whether Mr Ingham does speak for the majority of dental practitioners in England, but if his feelings are shared by many others, then there will be a devastating effect on the human resources available to the NHS to help achieve the vision of Options For Change. My view is that their fears and frustration must be allayed if Options for Change is to have any chance of success.

\section{THE FUTURE ROLE OF PRIMARY CARE TRUSTS (PCTS)}

Perhaps one of the key changes suggested in Options for Change is the change from centralisation of the provision of NHS dental care to local provision from local PCTs. 
The report also states that the most appropriate way of delivering service development (commissioning) and dental service provision could be through a host PCT which undertook the work on behalf of a number of surrounding PCTs. This approach is because of the 'apparent lack of specific dental knowledge within PCTs at present, recognising that new schemes of delivering primary dental care would need to be developed centrally with possible local variation.'

These may be visionary words, but do not address the real difficulty that both dentists and PCTs face. What dentists and patients need is a much clearer appreciation of the benefits of the proposed new system, which so far have not been forthcoming. Those volunteer PCTs who have been asked to develop commissioning options and new forms of contracting must present their results as soon as possible. Changes to remuneration can have a major de-stabilising effect in any organisation, and one year on things do not look any clearer.

\section{WHAT PATIENTS ARE SAYING}

Today much more emphasis is placed on the need for patients to be central to dental care practice. Currently patients are saying:

- it can be virtually impossible for adults to access NHS dental care

- finding a dentist can be difficult and time consuming

- changes are unclear and raise concerns over the cost of care

- making complaints is difficult

Does the report address these concerns? Sure enough, the commitment to quality is extremely well described in paragraph 2.4 of the report. Indeed the description of care that is 'of consistently high quality, delivered with technical competence by trained, motivated and engaged (dental) teams who put their patients' interests first. Care must be built around prevention and based where possible on lifelong care rather than episodic or reactive care' could equally apply to doctors. The report also makes clear that quality of care depends not just on the patient/clinician transaction, but is also about the quality of the organisation and the environment in which care takes place.

The sentiments are laudable, but will the resources be made available to enable these aims to be achieved? John Humphreys in a recent article in the Sunday Times drew attention to the woeful shortage of dentists prepared to work on the NHS. ${ }^{5}$

'Today a dentist gets a miserly £6.65 for a full check-up. If they do the same checkup privately they can charge about $£ 20$. What would you do if you were a dentist?
It's easy to prate about the public service ethic, but they have a business to run. New equipment is expensive. My own dentist keeps the drill his father used years ago. It's a bit like having an electric chair in the corner of your GP's consulting room. It makes you awfully grateful that he has spent so much on his fancy new gear.'

He too refers to the Health and Social Care Bill now going through parliament, which will sweep away the old payments system.

'Piece work will finally go. Primary care trusts and local health boards will have the legal obligation to provide "reasonable" dental care in their areas. They can set up dental practices of their own and pay dentists a salary to work in them, or draw up new contracts with existing practices. That's fine- but what is reasonable?'

His question gets to the heart of the practical problem facing PCTs. They are in a difficult situation too, faced with the new problem for them of providing access to 'reasonable' dental care. Discussions between the profession and PCTs must continue and be stepped up in all areas of the country.

\section{FINANCIAL RESOURCE IMPLICATIONS}

Next we come to the question of finance (ever the stumbling block in past negotiations over NHS dental provision). John Humphreys recognises that modern dental equipment is expensive, but essential for the practice of good dentistry. The British Dental Association has supported the principle of devolution of responsibilities and funding to a local level providing adequate funding is made available. In a recent policy document ${ }^{6}$ the Association said,

'Local management that is effective and efficient can focus on health inequalities but only if the professional staff, who deliver care, are adequately funded, equipped and rewarded to persuade them that the NHS offers good career prospects and a healthy environment in which to work.'

Politicians, through the Health Committee, have looked at the problems of NHS dentistry twice in the past ten years. Most recently they welcomed the new local focus for delivering dental care, but were concerned that health authorities did not "possess the levers they require to meet the objectives of the strategy' ${ }^{7}$ Levers are important. They are in the hands of politicians, managers, dentists, and, do not forget, patients. Patients are becoming more and more knowledgeable about health matters and will use their levers to obtain the health care they seek. Hopefully Options For Change will match its visionary suggestions with adequate funding - but not everyone is confident.

\section{PROGRESS IN DENTISTRY IN THE LAST 25 YEARS}

Options for Change is right to call for a modernised service for patients in the 21st Century. Any organisation must seek to modernise and address the needs of those it seeks to serve. But organisations also need to look back and see what has been achieved, in order to use this information as a springboard to develop further. By any yardstick, dentistry in Britain has made major developments over the last 25 years. The trend to group practices, the introduction of vocational training and the commitment to professional and personal development have dramatically improved the quality of large numbers of dental practices throughout the country. It is salutary to realise that many improvements, particularly in preventive dentistry and aspects of restorative dentistry and orthodontics, have come about because of the pressure of the marketplace and the influence of manufacturers. Fluoride has been used to prevent caries since the 1940s, but it was companies such as Colgate, Unilever, Procter Ct Gamble and Macleans who developed and marketed fluoride toothpaste in Britain in the 1970s. Their decisions have had a major impact on the prevention of caries. Adhesive dental materials have been developed by dental researchers but produced and marketed by dental companies, revolutionising the practice of restorative dentistry. Fixed appliance orthodontic treatment was relatively rare and unsophisticated in Britain 25 years ago, but has been transformed by the use of modern arch wires and bonding techniques. These, and many other developments, have been assimilated by the dental profession. The payment system has proved sufficiently flexible to enable many of these developments to be included in the fee scale. I hope this can continue under the proposed changes in the report.

\section{THE DENTAL PRACTICE BOARD}

One major change suggested in the report is the abolition of the Dental Practice Board, as its major role of centralised payment will no longer be needed. But the DPB has developed its role and in parallel with general developments in dentistry, expertise within the Dental Practice Board has broadened considerably over the last 25 years. Three areas of their work are of particular importance. Firstly, they have developed a system by which general dental practitioners can be paid, using either paper records or electronic transmission. The system is sophisticated and serves every dental practitioner in England and Wales contracted to the NHS. Secondly, their data analysis function has proved extremely useful in producing practice 
profiles and summaries for every district health authority. Thirdly they have a mechanism for fraud detection and probity which, as I know from personal experience as a member of the Professional Conduct Committee of the General Dental Council, provides information of the highest quality. Whatever information communication technology (ICT) infrastructure is devised, the financial probity, data analysis and fraud detection arrangements at present in place at the DPB will need to be retained, or replicated, within PCTs.

\section{THE GOVERNMENT'S IMPLEMENTATION PLANS}

Finally, what of the reasons behind the changes proposed in Options for Change? The Health Minister, Rosie Winterton, published implementation plans for NHS dentistry's future on August 12, 2003:

'We want patients to have easier access to a modernised locally run NHS dentistry service. These radical reforms, as well as addressing inequalities, improving access, improving the quality of NHS dental services and giving patients greater freedom of choice about where, when and how they use dental services, are aimed at improving the working lives of dentists and their teams in the NHS. As with the rest of the
NHS, dentistry must be modernised if it is to continue meeting the needs of today's patients. The way to make dentistry more responsive to patients' needs is to empower local services. That is why we are devoting financial resources and commissioning the local Primary Care Trusts (PCTs). For the first time, the NHS will hold the funding for NHS dentistry. And working with local patients and dentists, PCTs will be able to plan and develop local services to meet local needs.'

I believe that Options for Change is the Government's version of a strategic response to practitioners' wholesale moves into the private sector.

\section{CONCLUSION}

In this personal review I have touched on a number of aspects and thoughts one year after publication of Options For Change. Some comments may appear a trifle negative, but this is only a reflection of attitudes, reports and comments I have experienced. The future is uncertain, especially the fact that so much is still unknown.

The start date for local commissioning is April 2005, less than 18 months away. The Government's timetable for implementation is extremely tight, especially as the arrival of the legislation came after the decision to go ahead with field sites for Options for Change had been made. One year on from its launch the devil is still in the detail. Support and resources at a local level are crucial if these major changes are going to make a real difference for both dentists and patients. Dentists must make the most of the opportunity to inform PCTs of the dental needs of the community. Commissioners and managers will have to work hard, in an open and transparent way, if the public and the profession are to be reassured about the new NHS Dental Service for England.

1. NHS Dentistry: Options for Change. London: Department of Health, 2002. www.doh.gov.uk/cdo/optionsforchange

2. Pitts, N. NHS Dentistry: Options for Change in context - a personal overview of a landmark document and what it could mean for the future of dental services. BrDent J 2003; 195: 631-635.

3. Dental Strategy Review Group Report. Department of Health, 1981.

4. Ingram, N End of NHS dentistry. Letter to the Editor Daily Telegraph, Aug 92003.

5. Humphrys, J U. Open wide - you may have to give up your dental care. Sunday Times, Aug 32003.

6. British Dental Association. Policy document: Modern NHS Primary Dental Care, Organisation and Development 2001-2005, 2001.

7. House of Commons Session 2000/01 Health Committee: Access to NHS Dentistry HC247.

8. BDA News, September 2003; 16:2-3. 